\title{
Influence of Laser-Induced Bubble Formation on Laser Chemical Machining
}

\author{
Marcel Simons' ${ }^{1}$, Tim Radel ${ }^{1}$, Raj Shanta Kajsaravally², Frank Vollertsen ${ }^{1,3}$ \\ ${ }^{1}$ BIAS-Bremer Institut für angewandte Strahltechnik, Bremen, Germany \\ ${ }^{2}$ Department of Communications Engineering, Bremen, Germany \\ ${ }^{3}$ Faculty of Production Engineering-Mechanical Engineering \& Process Engineering, University of Bremen, Bremen, Germany \\ Email: simons@bias.de
}

How to cite this paper: Simons, M., Radel, T., Kajsaravally, R.S. and Vollertsen, F. (2020) Influence of Laser-Induced Bubble Formation on Laser Chemical Machining. Journal of Surface Engineered Materials and Advanced Technology, 10, 21-33. https://doi.org/10.4236/jsemat.2020.102002

Received: February 6, 2020

Accepted: March 17, 2020

Published: March 20, 2020

Copyright (c) 2020 by author(s) and Scientific Research Publishing Inc. This work is licensed under the Creative Commons Attribution International License (CC BY 4.0).

http://creativecommons.org/licenses/by/4.0/

\begin{abstract}
Laser Chemical Machining (LCM) is a non-conventional processing method, which enables very accurate and precise ablation of metallic surfaces. Material ablation results from laser-induced thermal activation of heterogeneous chemical reactions between electrolytes and a metallic surface. However, when processing metallic surfaces with LCM, large fluctuations in ablation quality can occur due to rising bubbles. The formation of bubbles during laser chemical machining and their influence on the ablation quality has not been investigated. For a more detailed investigation of the bubbles, ablation experiments on Titanium and Ceramic under different thermal process conditions were performed. The experiments were recorded by a high-speed camera. The evaluation of the video sequences was performed using Matlab. The resulting bubbles were analyzed regarding their size and frequency. The results show that boiling bubbles formed on both materials during processing. Titanium also produces smaller bubbles, which can be identified as process bubbles according to their size. Furthermore, it was found that undisturbed laser chemical ablation can be achieved in the presence of a boiling process, since both boiling bubbles and process bubbles were detected during machining within the process window.
\end{abstract}

\section{Keywords}

Micro Machining, Laser Micro Machining, Laser Chemical Removal, Nucleate Boiling, Highspeed Videography

\section{Introduction}

Constantly smaller components increase the demands of industrial manufacturing processes. Traditionally used manufacturing processes are increasingly 
reaching their limits in terms of complexity and size [1].

Alternative machining processes, especially for metal workpieces, are the so-called non-conventional machining processes. Non-conventional machining processes are alternative machining processes, especially for metal workpieces and among them, laser chemical machining (LCM) is very important [2]. Laser chemical machining combines the advantages of laser processing, such as precise and localized energy input, and the advantages of electrochemical processing with a gentle energy impact without significant heat impact [3], which is why the unprocessed microstructure of the materials is not affected [4].

In laser chemical machining, the workpiece is irradiated by a laser, which introduces local, precise and adequate energy in the form of heat into the workpiece. The workpiece is surrounded by electrolytes [5]. Depending on the laser intensity applied and the spot size of the laser, the induced temperature fields on the workpiece change the electrochemical potential that an anodic material dissolution is induced resulting in a material removal at the surface of the workpiece [6].

Within a suitable process window, a gentle ablation is generated without a detectable heat-affected zone and without remelting processes in the material, which is the main advantage of laser chemical machining compared to other laser based non-conventional ablation processes [4].

The process window of the laser chemical machining is strongly influenced by a variety of parameters [7], such as laser power, flow rate of the electrolyte, machining speed that is why irregularities of the ablation can occur when leaving the process window [8]. Since laser chemistry is mainly a temperature-dependent process, the quality of the ablation generated is mainly dependent on electrolyte boiling, along with the boiling bubble size and the dynamic behavior of the boiling bubbles [9].

In this work, the formation and the behavior of the bubbles are therefore examined more closely in order to identify the relationship between bubble formation and ablation quality. First, ablations with a variation of the process parameters, e.g. laser power and machining speed, are generated and recorded by a high-speed camera. The recorded videos are then analyzed with a focus on the bubble diameter, the adhering time of the bubbles on the workpiece and the bubble size after the bubble has detached from the workpiece.

\section{Experimental Set-Up}

A continuous-wave $(\mathrm{cw})$ fiber laser with a wavelength of $1080 \mathrm{~nm}$ is used as the laser beam source. The Gaussian laser radiation is first collimated to a beam diameter of $8 \mathrm{~mm}$, then further reduced to $2 \mathrm{~mm}$ by an inverted telescope and then focused with a lens system with a focal length of $53 \mathrm{~mm}$. With this setup a focus diameter of $30 \mu \mathrm{m}$ was realized.

Titanium 3.7024 was selected as treatment material, with a size of $20 \mathrm{~mm} \times 20$ $\mathrm{mm} \times 1 \mathrm{~mm}$. Ceramic $\left(\mathrm{Al}_{2} \mathrm{O}_{3}\right)$ with a comparable absorption, surface quality and heat conductivity were selected as reference material, see Table 1 . Reason for 
Table 1. List of material properties.

\begin{tabular}{cccc}
\hline Parameter & Unit & Titanium & Ceramic \\
\hline Surface quality $S_{a}$ & $\mu \mathrm{m}$ & 1.47 & 1.47 \\
Heat conductivity $\lambda$ & $\mathrm{W} /(\mathrm{mK})$ & 22 & 23 \\
Absorption & - & 0.43 & 0.41 \\
\hline
\end{tabular}

this is that the surface quality is crucial for the number of nuclei. This means that more nuclei are formed in the recess on rougher surfaces. In addition, the absorption determines how much thermal power is introduced into the workpiece. The resulting temperature field correlates directly with the number of bubbles and the bubble diameter.

The laser powers were chosen in such a way that they cover all three regimes, no removal, non-disturbed removal and disturbed removal, of laser chemical material processing [7].

The workpieces were embedded in a closed chemical cell through which a 5 molar phosphoric acid was constantly flowing as electrolyte, see Figure 1. The flow rate of the acid was $3 \mathrm{~m} / \mathrm{s}$.

The electrolyte height of approx. $20 \mathrm{~mm}$ on the workpiece impairs the power density of the laser beam on the workpiece with a transmission of 0.68 . During the experiments the movement of the laser processing head was ensured by $\mathrm{x}$ and $y$-axes. For investigations linear ablation lines were generated with velocities of $50 \mu \mathrm{m} / \mathrm{s}$ and $100 \mu \mathrm{m} / \mathrm{s}$, see Table 2 .

A high-speed camera including a band pass filter was used to record the interaction zone between the electrolyte and the workpiece during the process, compare Figure 1. The shadow method was used for video recording. It describes a transmitted light method in which refractive index changes are made visible in transparent shadows, see Figure 2.

An illumination laser was used as the light source. The illumination unit consists of a pulsed diode laser with a wavelength of $810 \mathrm{~nm}$, a widening optic for uniform illumination of the interaction zone.

The complete experimental set-up and the chosen experiment parameters are the same for all experiments, it is only varied in the laser power and the machining speed, see Table 2 and Figure 1.

The high-speed images were taken with $256 \times 256$ pixels and frame rates of 22,000 frames per second. One camera pixel corresponded to a square surface with a side length of $1.75 \mu \mathrm{m}$. The video sequences were evaluated using Matlab.

As shown in the shadow images, Figure 2, the workpiece represents the lower dark area and the electrolyte represents the bright area due to its transparency. On the electrolyte side, induced transmission optical densities can now be detected during the process. The density differences show the forming bubbles and streaks. All the frames were individually separated and analyzed. The recorded images were first converted into binary formats and edges were detected, see Figure 2. The geometrically closed surfaces were assumed to be circular and evaluated as bubbles. 


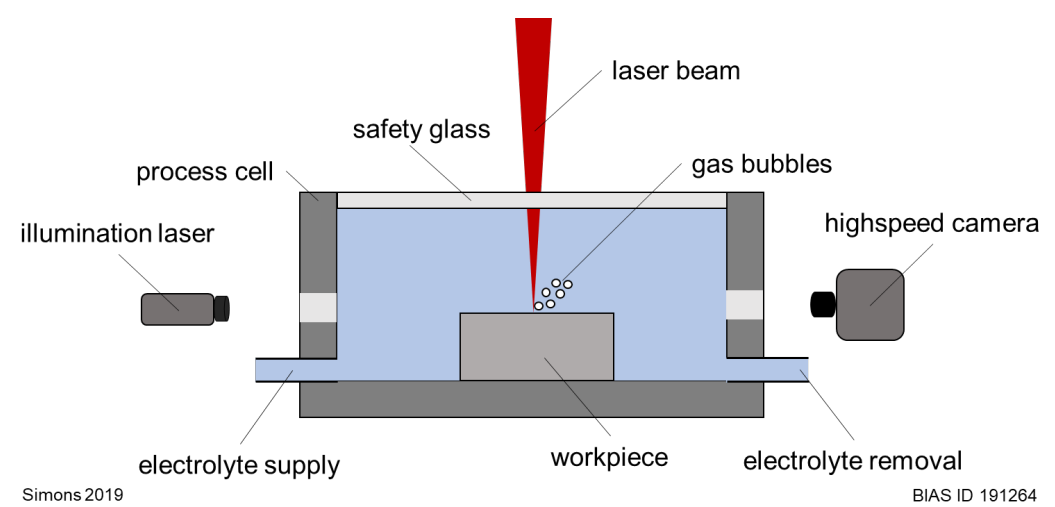

Figure 1. Schematic representation of the experimental set up.
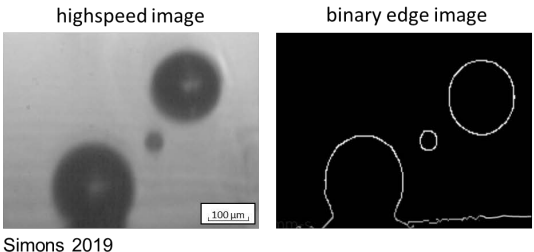

analyzed image

Simons 2019

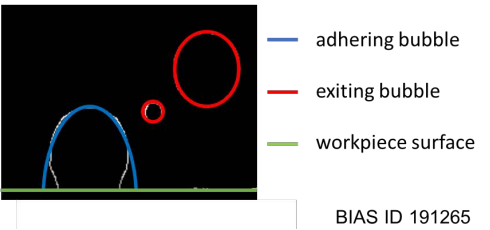

Figure 2. Presentation of the procedure for the analysis of high-speed videography with the help of Matlab.

Table 2. List of process parameters used for experimental investigation.

\begin{tabular}{cccc}
\hline & Parameter & Unit & Value \\
\hline Laser beam & wavelength & $\mathrm{nm}$ & 1080 \\
& laser power & $\mathrm{W}$ & $0.6 \cdots 1.8$ \\
& focus spot diameter & $\mu \mathrm{m}$ & 30 \\
& processing speed & $\mu \mathrm{m} / \mathrm{s}$ & $50 \cdots 100$ \\
Phosphoric acid $^{\text {continuous wave) }}$ & concentration & $\mathrm{mol} / \mathrm{L}$ & 5 \\
& boiling temperature & ${ }^{\circ} \mathrm{C}$ & 104 \\
& transmission coefficient & - & 0.68 \\
& layer height & $\mathrm{mm}$ & 20 \\
& flow speed & $\mathrm{m} / \mathrm{s}$ & 3 \\
\hline
\end{tabular}

In the evaluation, a distinction was made between two types of bubbles, the adhering bubbles and the exiting bubbles. An adhering bubble was detected when the bubble was in direct contact with the workpiece surface. The bubble diameter of the adhering bubble was determined at the moment of detachment, so that the bubble diameter of adhering bubbles is equal to the maximum bubble diameter. An exiting bubble was determined when the bubble lost contact with the workpiece and is at least $75 \mu \mathrm{m}$ above the workpiece. The reason for this is that the bubbles collapse after the ascent, so the bubble size of the exiting bubbles was detected after the collapse. Before the collapse the bubbles have the same diameter as the adhering bubbles. Bubbles with a minimum diameter of 3 $\mu \mathrm{m}$ could be detected. In addition to the sizes, the number of both adhering and exiting bubbles was determined. With the help of the number of adhering bub- 
bles and the recorded time period ( $5 \mathrm{~s}$ ) the frequencies of the adhering bubbles were calculated (formation frequency).

Additionally, the time in which the workpiece surface is covered with bubbles was determined (bubble coverage time). For this purpose, the time was detected in which no bubble adheres to the surface of the workpiece in the area of the laser irradiation.

\section{Results}

\subsection{Influence of Laser Power on Bubble Formation}

Based on the process parameters in Table 2, the average diameters of adhering and exiting bubbles were plotted in Figure 3.

As can be seen in Figure 3, with increasing laser power, the adhering bubble averages shift to larger bubble diameters, which in comparison mean that bubbles with smaller diameters occur at lower laser powers. With the process parameters shown in Figure 3, a minimum bubble diameter of $4 \mu \mathrm{m}$ could be measured and a maximum diameter of $271 \mu \mathrm{m}$.

If one considers the exiting bubbles based on Figure 3, the analyzed bubble diameters are essential smaller than those of the adhering bubbles. Moreover, it becomes clear that the averages are almost similar for all laser powers. Hence they are independent of the laser power used.

Figure 4 shows some exemplary image sequences which illustrate the typical dynamics of bubble formation. The image sequences of low laser power clearly show that the bubble dynamics are very low. Compared to image sequences with higher laser power, the workpiece surface is covered with bubbles over shorter periods of time, which can also be seen in Figure 5. Figure 5 shows the time during which the surface of the workpiece is covered with bubbles in relation to the experimental time.

It can be observed that the growth time of the bubbles in the low laser power range is many times longer, see Table 3 , a smaller quantity of bubbles is formed regarding to the processing time. The bubbles with a low diameter initially rise

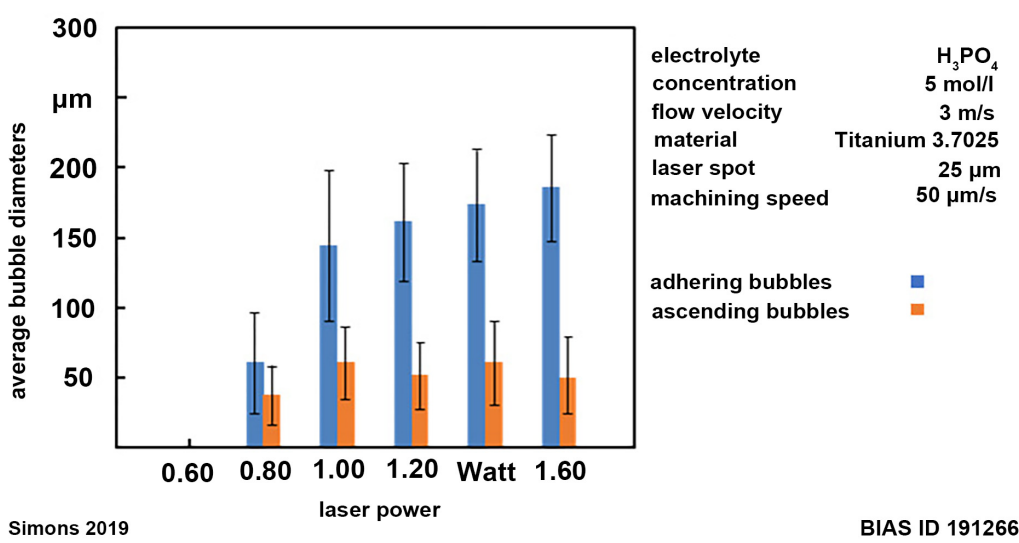

Figure 3. Representation of the average bubble diameters during laser chemical machining at a machining speed of $50 \mu \mathrm{m}$ (Titanium). 

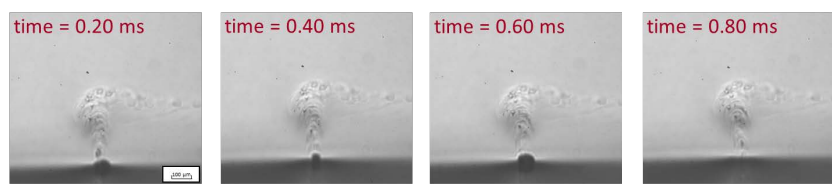

laser energy: machining speed

$0.8 \mathrm{~W}$ $50 \mu \mathrm{m} / \mathrm{s}$

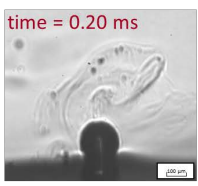

time $=0: 40 \mathrm{~ms}$

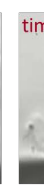

electrolyte

flow velocity

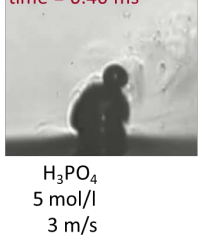

time $=0.60 \mathrm{~ms}$

time $=0.80 \mathrm{~ms}$

laser energy: machining speed

$1.6 \mathrm{~W}$
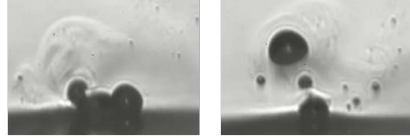

material

Titanium 3.7025

laser spot

$25 \mu \mathrm{m}$ simons 2019

Figure 4. Formation of bubble at interaction zone with a machining speed of $50 \mu \mathrm{m} / \mathrm{s}$ (Titanium).
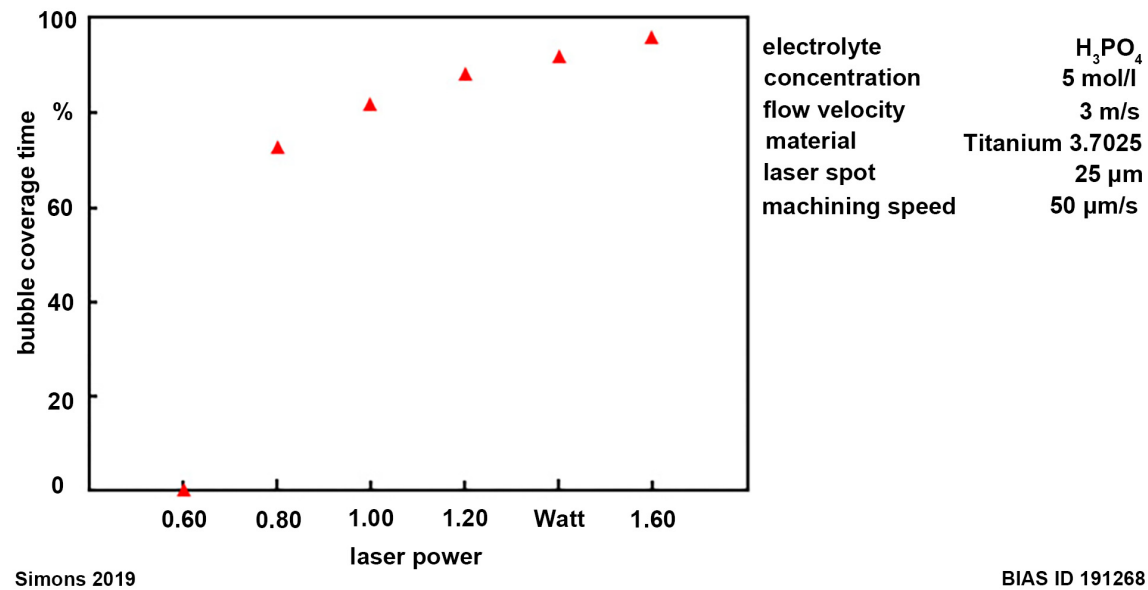

Figure 5. Evaluation of the time affected by bubbles and the time free of bubbles (Titanium).

Table 3. Evaluation of the number of adhering bubbles, exiting bubbles, formation frequency and surface temperature calculated according to [7] with a machining speed of 50 $\mu \mathrm{m} / \mathrm{s}$ (Titanium).

\begin{tabular}{ccccc}
\hline $\begin{array}{c}\text { laser power } \\
{[\mathrm{W}]}\end{array}$ & $\begin{array}{c}\text { surface temperature } \\
{\left[{ }^{\circ} \mathrm{C}\right]}\end{array}$ & $\begin{array}{c}\text { number of adhering } \\
\text { bubbles }\end{array}$ & $\begin{array}{c}\text { number of exiting } \\
\text { bubbles }\end{array}$ & $\begin{array}{c}\text { frequency } \\
{[1 / \mathrm{s}]}\end{array}$ \\
\hline 0.60 & 85 & 0 & 0 & 0 \\
0.80 & 104 & 1053 & 5901 & 210.6 \\
1.00 & 123 & 2261 & 12,159 & 452.2 \\
1.20 & 148 & 3516 & 17,589 & 703.2 \\
1.40 & 171 & 4615 & 26,002 & 923 \\
1.60 & 192 & 5977 & 30,138 & 1195.4 \\
\hline
\end{tabular}

vertically upwards, where they are captured by the flow at a certain height (200 $\mu \mathrm{m})$ and transported away, as can be seen in Figure 4.

The bubbles of larger diameters collapse very quickly. This results in pressure wave. The collapsed bubble therefore divides into several small diameter bub- 
bles. These resulting bubbles are detected as exiting bubbles. They act as nuclei for a new bubble formation or they are pushed away by the collapse pressure wave and transported away by the electrolyte flow. These processes are repeated over the entire processing time for both small and large diameter bubbles, but they are not periodic.

At low laser powers the number of adhering bubbles and accompanied the formation frequency is much smaller compared to higher laser powers, see $\mathrm{Ta}$ ble 3. Table 3 shows the surface temperatures of the workpiece in the focal spot zone based on [7], assuming the simplification that the bubbles do not interfere with the absorption and thus do not influence the surface temperatures. As can be seen, this correlates directly with the laser power and thus also with the number of bubbles.

A comparison of Figure 3 and Figure 6 shows the influence of the machining speed on bubble formation. The average value of adhering bubbles in Figure 6 is in a much smaller diameter range than in Figure 3. The smallest measured adhering bubble diameter based on the process parameters in Figure 6 is $3 \mu \mathrm{m}$ and the largest measured diameter is $257 \mu \mathrm{m}$.

With the diameters of the exiting bubbles, there are no significant changes when the machining speed is increased.

Figure 7 shows that due to the smaller bubbles, the adhering time of the bubbles relative to the experimental time is significantly reduced. As the laser power increases, however, the adhering time increases linearly as shown in Figure 3, as well.

If one compares the image sequences from Figure 4 and Figure 8, one can see that the bubble size also increased with increasing laser power. This effect occurs independently of the machining speed. The image sequences clearly show that the dynamic behavior of the bubbles decreases significantly with increasing machining speed.

A quantitative difference can be seen. A higher machining speed results in a lower number of boiling bubbles, which collapse and accordingly a lower number of exiting bubbles is produced, see Table 4 .

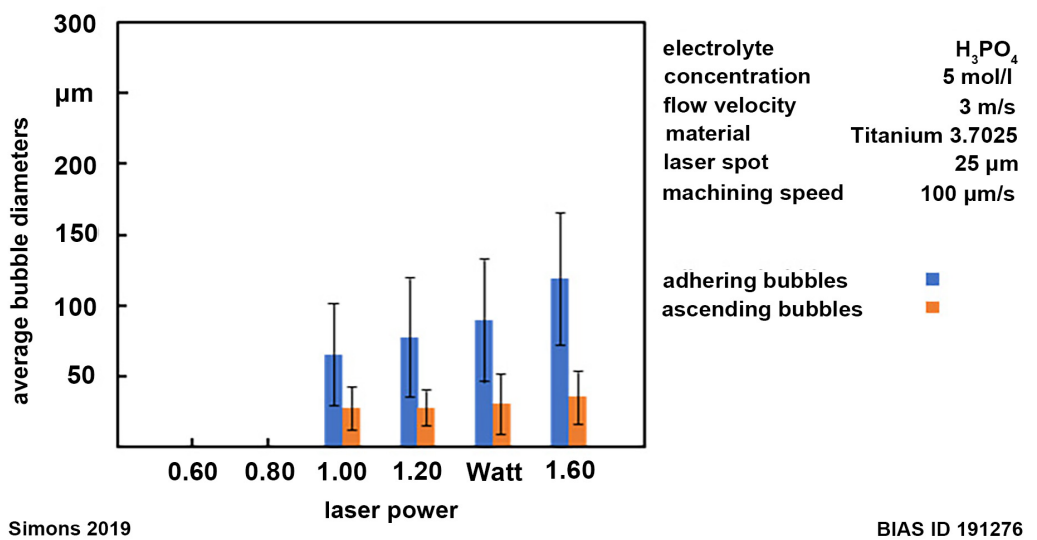

Figure 6. Representation of the average bubble diameters during laser chemical machining at a machining speed of $50 \mu \mathrm{m} / \mathrm{s}$ (Titanium). 

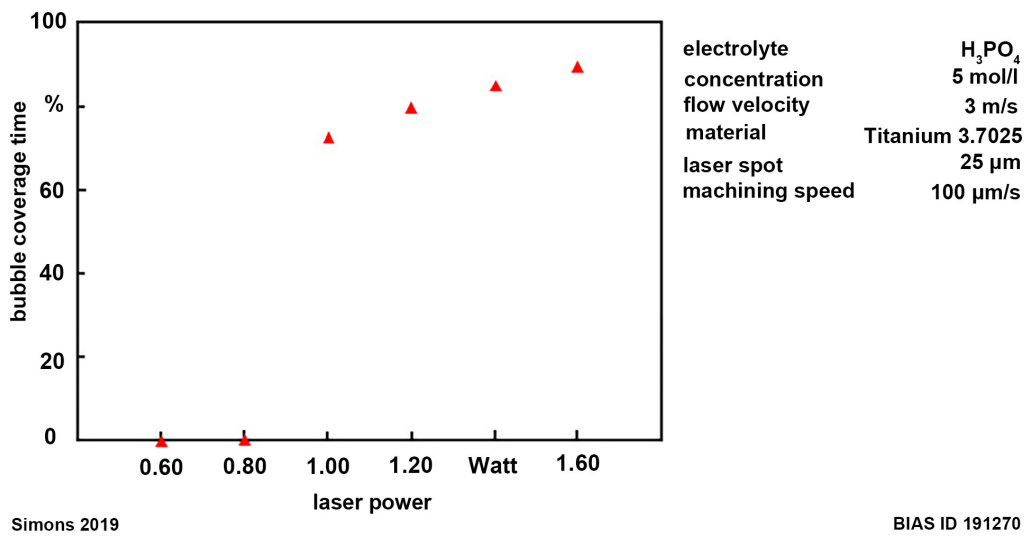

Figure 7. Evaluation of the time affected by bubbles and the time free of bubbles (Titanium).
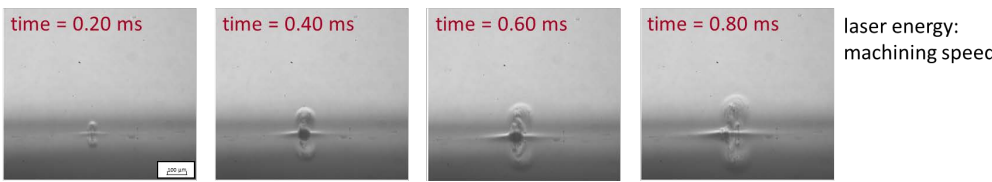

$1.0 \mathrm{~W}$ $100 \mu \mathrm{m} / \mathrm{s}$

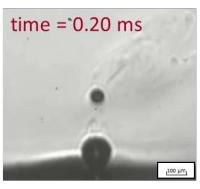

electrolyte concentration flow velocity

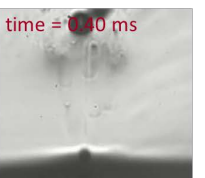
$\mathrm{H}_{3} \mathrm{PO}_{4}$ $5 \mathrm{~mol} / \mathrm{l}$

$3 \mathrm{~m} / \mathrm{s}$

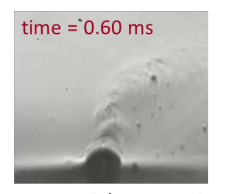

time $=0.80$ mis $\quad 1.6 \mathrm{~W}$

material Titanium 3.7025

laserspot $\quad 25 \mu \mathrm{m}$

Figure 8. Formation of bubbles at interaction zone with a machining speed of $100 \mu \mathrm{m} / \mathrm{s}$ (Titanium).

Table 4. Evaluation of the number of adhering bubbles, exiting bubbles, formation frequency and surface temperature [7] with a machining speed of $100 \mu \mathrm{m} / \mathrm{s}$ (Titanium).

\begin{tabular}{ccccc}
\hline $\begin{array}{c}\text { laser power } \\
{[\mathrm{W}]}\end{array}$ & $\begin{array}{c}\text { surface temperature } \\
{\left[{ }^{\circ} \mathrm{C}\right]}\end{array}$ & $\begin{array}{c}\text { number of adhering } \\
\text { bubbles }\end{array}$ & $\begin{array}{c}\text { number of exiting } \\
\text { bubbles }\end{array}$ & $\begin{array}{c}\text { frequency } \\
{[1 / \mathrm{s}]}\end{array}$ \\
\hline 0.60 & 85 & 0 & 0 & 0 \\
0.80 & 104 & 0 & 0 & 0 \\
1.00 & 123 & 1648 & 8654 & 329.6 \\
1.20 & 148 & 2823 & 15,305 & 564,6 \\
1.40 & 171 & 3702 & 21,641 & 740,4 \\
1.60 & 192 & 5069 & 28,613 & 1013.8 \\
\hline
\end{tabular}

Irrespective of the machining speed, the number of bubbles produced increases with the laser power.

\subsection{Differences in Bubble Properties}

To characterize the different bubbles inert Ceramic was irradiated additional to Titanium. In experiments with low laser powers $(0.6 \mathrm{~W}$ and $0.8 \mathrm{~W})$, no evaluable 
bubbles were formed. An evaluation of experiments could be carried out only at higher laser powers, as shown in Figure 9 and Figure 10. It is important to note that the Ceramic used has the same thermal conductivity as Titanium. For this reason, based on the calculations of [7], the surface temperatures of the Ceramic material are the same as those of Titanium, see Table 2 and Table 3.

It is noticed that bubbles of larger diameter are produced by irradiating Ceramic. The smallest detected adhering bubble had a diameter von $75 \mu \mathrm{m}$. The largest measured diameter of adhering bubbles is $269 \mu \mathrm{m}$, which is comparable to the adhering bubble diameters on Titanium.

The observations at higher machining speeds are analogous to those for machining Titanium, compare Figure 6 and Figure 11. The time periods, in which the workpiece is free of bubbles see Figure 12 are also similar to those shown in Figure 7. Even at a higher machining speed, no adhering bubble diameter below $75 \mu \mathrm{m}$ was detected on Ceramic. The highest measured adhering bubble diameter is $262 \mu \mathrm{m}$, which is also comparable to the results shown before.

\section{Discussion}

In the LCM process, bubbles of different sizes are produced which reduce the ablation quality and thus represent a barrier to laser chemical machining [8]. Analogous to the assumptions in [9], different size ranges of the bubbles were detected during the machining of Ceramics and Titanium, compare Figure 3 and Figure 9. This points to two different types of bubbles, process bubbles and boiling bubbles.

Process bubbles are formed due to the chemical reactions and are filled with hydrogen. These cannot be prevented during the laser chemical processing of metallic materials, such as Titanium, see Figure 3. The boiling bubbles are caused by the thermal influence of the laser on the workpiece surface, regardless of the workpiece material. The workpiece is heated in the interaction zone of the laser and the heat is transferred to the electrolyte. The boiling temperature of the
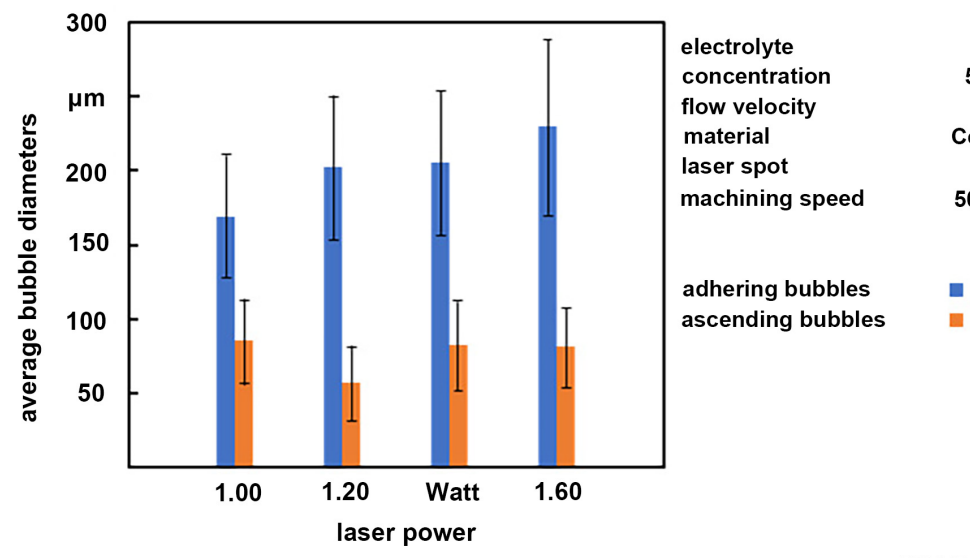

Figure 9. Representation of the average bubble diameters during laser chemical machining at a machining speed of $50 \mu \mathrm{m} / \mathrm{s}$ (Ceramic). 


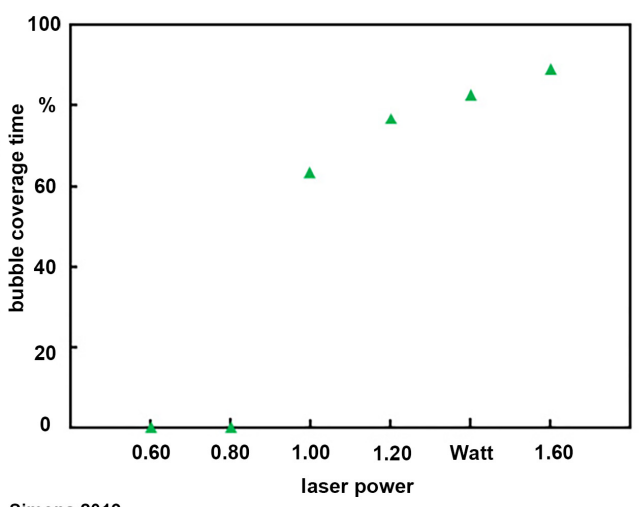

electrolyte

concentration

flow velocity

material

$5 \mathrm{~mol} / \mathrm{l}$

$3 \mathrm{~m} / \mathrm{s}$

laser spot

Ceramic

machining speed

$25 \mu \mathrm{m}$

Simons 2019

BIAS ID 191273

Figure 10. Evaluation of the time affected by bubbles and the time free of bubbles (Ceramic).
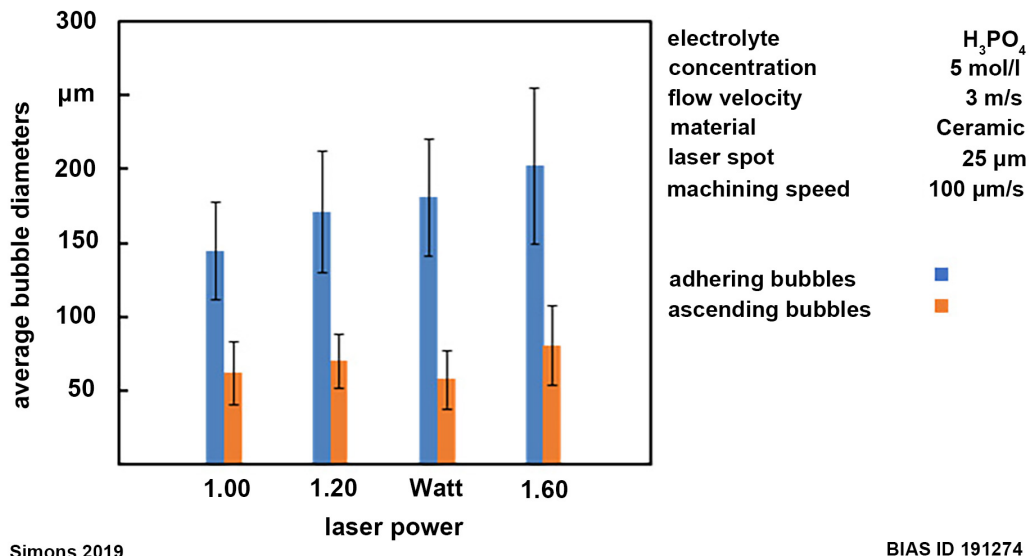

BIAS ID 191274

Figure 11. Representation of the average bubble diameters during laser chemical machining at a machining speed of $100 \mu \mathrm{m} / \mathrm{s}$ (Ceramic).
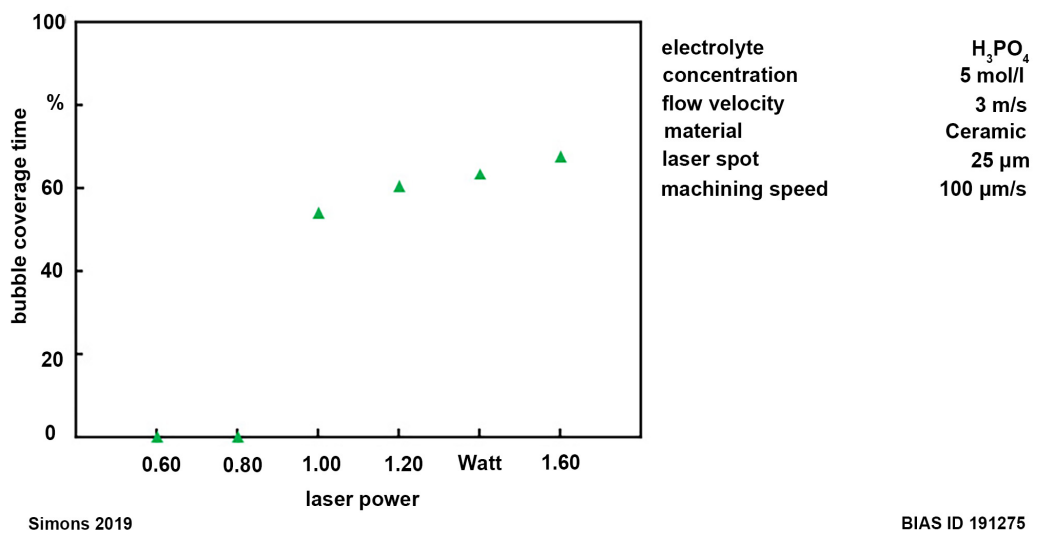

Figure 12. Evaluation of the time affected by bubbles and the time free of bubbles (Ceramic).

electrolyte is locally exceeded, so that bubble boiling occurs. When looking at the bubble sizes during the heating of Ceramics, see Figure 9, it is noticeable that bubbles of larger diameters are formed compared to the machining of Titanium, see Figure 3. Since no process bubbles are formed during the heating of Ceramics, 


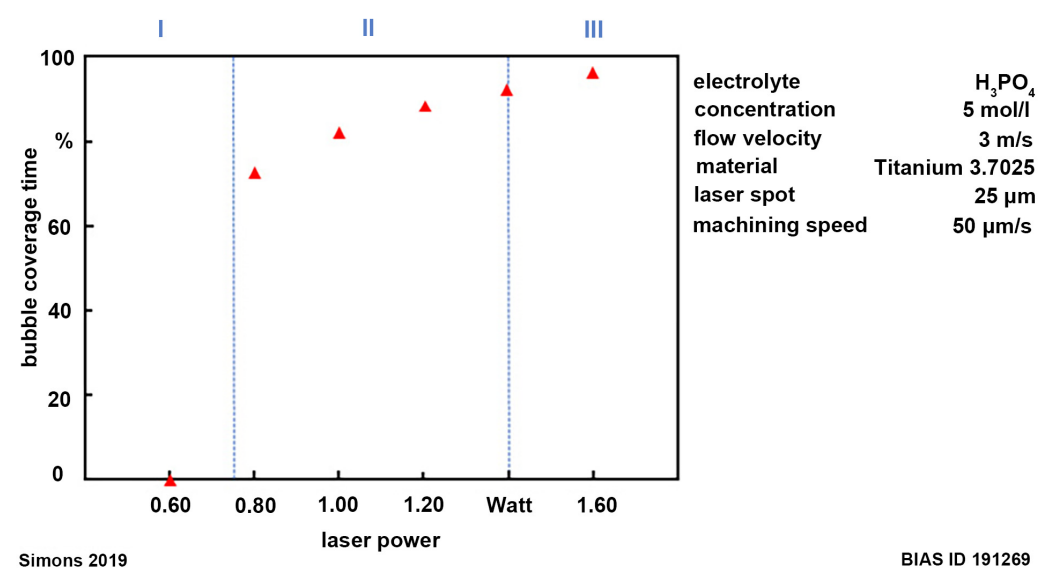

Figure 13. Representation of the time during which the workpiece surface is covered by bubbles, including the removal regimes from [9].

it can be concluded that bubbles with smaller diameters are process bubbles and bubbles with large diameters are boiling bubbles.

As can be seen in Figure 3 and Figure 4, high laser powers cause large diameters of adhering bubbles. This is due to the increased local temperature distribution on the workpiece. In [8] there is a proportional relationship between the temperature on the workpiece and the laser power. Due to heat transfer mechanisms, the electrolyte temperature also increases locally and a boiling process with increased bubble dynamics occurs.

If one considers the different processing regimes based on the definitions in [9], marked in Figure 13, no bubbles are formed if the ablation is not visible. In this case, the surface temperatures are not sufficient to locally break up the passive layer and initiate the chemical reactions necessary for ablation. If the temperature of the laser power is calculated in the "no removal" regime, see Table 3 , the boiling temperature of the electrolyte is not reached.

By increasing the laser power, the undisturbed area is reached. If the surface temperatures of the workpiece are higher than the boiling temperature, see $\mathrm{Ta}$ ble 3 and Table 4, local overheating of the electrolyte occurs, resulting in boiling bubbles.

If one looks at the recorded bubbles and the time in which the workpiece surface is covered by bubbles, see Figure 3 and Figure 13, one can see that both the bubble size and the time in which the workpiece surface is covered by bubbles increases, so that a boiling process can be assumed. From this it follows that boiling bubbles are also present in the undisturbed state and thus undisturbed laser chemical processing under ambient conditions is possible if boiling bubbles are present.

If the laser power is further increased, the disturbed state is reached. It is visible that due to a higher surface temperature, see Table 3 and Table 4, the number of boiling bubbles, the size of the boiling bubbles and the time in which the workpiece is covered by bubbles increases, see Figure 3 and Figure 13. These can be seen analogously at a higher processing speed of $100 \mu \mathrm{m} / \mathrm{s}$. 
Looking at the regimes of undisturbed and disturbed ablation, the formation of boiling bubbles can be seen in both regimes. This indicates that bubble formation and the boiling process itself is not an indication of the quality of ablation.

\section{Conclusions}

It could be shown that two different types of bubbles, process bubbles and boiling bubbles, occur during laser chemical processing, while the process bubbles do not affect the ablation quality.

Using video graphic analysis of bubble formation during chemical processing with the laser, it was shown that undisturbed ablation is possible even in the presence of boiling bubbles.

\section{Acknowledgements}

This work has been funded by the Project 403820352 "Steigerung der Prozesseffizienz der laserchemischen Bearbeitung durch Vermeidung der gasblasenbedingten Abtragsstörungen". The authors gratefully acknowledge the financial support by the Deutsche Forschungsgemeinschaft.

\section{Conflicts of Interest}

The authors declare no conflicts of interest regarding the publication of this paper.

\section{References}

[1] Martin, A. and FitzGerald, B. (2013) Process over Platforms: A Paradigm Shift in Acquisition through Advanced Manufacturing, Center for a New American Security.

[2] Manjaiah, M., Narendranath, S. and Basavarajappa, S. (2014) Review on Non Conventional Machining of Shape Memory Alloys. Transactions of Nonferrous Metals Society of China, 24, 12-21. https://doi.org/10.1016/S1003-6326(14)63022-3

[3] Eckert, S. and Vollertsen, F. (2018) Mechanisms and Processing Limits of Surface Finish Using Laser-Thermochemical Polishing. Annals-Manufacturing Technology, 67, 201-204. https://doi.org/10.1016/j.cirp.2018.04.098

[4] Messaoudi, H., Böhmermann, F., Mikulewitsch, M., von Freyberg, A., Fischer, A., Riemer, O. and Vollertsen, F. (2018) Chances and Limitations in the Application of Laser Chemical Machining for the Manufacture of Micro Forming Dies. 5 th International Conference on New Forming Technology, 190, 8. https://doi.org/10.1051/matecconf/201819015010

[5] Stephen, A., Lilienkamp, T., Metev, S. and Sepold, G. (1999) Laser-Assisted Micromachining of Large-Area 3D Metallic Microparts. Proc. $1^{\text {st }}$ Int. Conf. Euspen (Shaker Verlag), Bremen, May 31-4 June 1999, 20-23.

[6] Bäuerle, D. (2011) Laser Processing and Chemistry. Springer Verlag. https://doi.org/10.1007/978-3-642-17613-5

[7] Mehrafsun, S. and Vollertsen, F. (2013) Disturbance of Material Removal in Laser-Chemical Machining by Emerging Gas. CIRP Annals, 62, 195-198. https://doi.org/10.1016/j.cirp.2013.03.030

[8] Messaoudi, H., Eckert, S. and Vollertsen, F. (2017) Thermal Analysis of Laser Chemical Machining: Part 1: Static Irradiation. Journal of Materials Science and 
Surface Engineering, 5, 685-691. https://doi.org/10.4236/msa.2017.810049

[9] Mehrafsun, S. and Messaoudi, H. (2018) Dynamic Process Behavior in Laser Chemical Micro Machining of Metals. Journal of Manufacturing and Materials Processing, 2, 54-72. https://doi.org/10.3390/jmmp2030054 